\title{
The Roles of Cloud-Based Supply Chain Integration on Firm Performances and Competitiveness
}

\author{
Alie Wube Damtew ${ }^{1}$, Tafesse Borena ${ }^{2}$, Yitagesyu Yilma ${ }^{3}$ \\ ${ }^{1}$ School of Mechanical and Industrial Engineering, Kombolcha Institute of Technology (KIOT), Wollo University, Dessie, Ethiopia \\ ${ }^{2}$ Industrial Engineering, Saint Mary's University, San Antonio, USA \\ ${ }^{3}$ Industrial Engineering, Addis Ababa Science and Technology University, Addis Ababa, Ethiopia
}

Email address:

alie.wube@aait.edu.et(A.W. Damtew),wubealie@gmail.com(A.W. Damtew)

\section{To cite this article:}

Alie Wube Damtew, Tafesse Borena, Yitagesyu Yilma. The Roles of Cloud-Based Supply Chain Integration on Firm Performances and Competitiveness. International Journal of Industrial and Manufacturing Systems Engineering. Vol. 6, No. 3, 2021, pp. 49-58.

doi: 10.11648/j.ijimse.20210603.12

Received: September 9, 2021; Accepted: October 19, 2021; Published: October 30, 2021

\begin{abstract}
Cloud computing systems have emerged as a useful technology that contributes to this optimization SCI process by providing infrastructure, platform, and software solutions for the whole supply chain via the internet. But in developing regions like Ethiopia, there's a weak traditional, fragmental, non-integrated, weak, and underdeveloped supply chain process. There's still space for research on real industrial applications where Ethiopian firms strive for cloud-based integration and implement new models and integration strategies practices in their supply chains. Thus, this study is designed to investigate the impacts of cloud computing technology on the supply chain integration process to improve the performance and comparative advantage of manufacturing industries in general, and the Ethiopian basic metal industry in particular. Using primary and literature survey data, the study has been carried-out through SPSS correlation and regression analysis methods. The study shows that the adoption and utilization of cloud-based services in supply chain integration leads to improvements in both the performance and competitiveness of the firm at regional and global levels. In particular, the cloud-based supply chain integration strategies provide enhanced resource utilization, reduce the constraints on information flow in the firm, increase product and service visibility, and create flexibility within systems within supply chain partners, and manufacturing industries as a whole. According to these investigations, cloud computing has a great impact on supply chain integrations so as to improve the performance and comparative advantage of the firm. Thus, effective and efficient utilization of cloud-based supply chain integrations has a higher positive impact on firm performance and competitiveness. Furthermore, this study demonstrates that data privacy, information risk, security issues, cloud architecture, process customization, and trust among collaborators must be prioritized for long-term supply chain systems and joint ventures in cloud-based supply chain integration.
\end{abstract}

Keywords: Supply Chain Integration, Cloud Computing, Comparative Advantage, Supply Chain Security, Manufacturing Performance

\section{Introduction}

Manufacturers can get ahead of the game and better address demand by adopting the most recent and advanced technologies. By incorporating new technology into their facilities, manufacturers are able to improve and enhance operational activities, processes, and the general quality of their products, while saving time and reducing costs. Commonly, sweeping technologies have driven the manufacturing sector to a very new level of optimal functionality where innovation and opportunities are pursued constantly. Cloud computing, the Internet of things, nanotechnology, and 3D printing are a number of the best technologies that are trending across the manufacturing landscape within this digital economy. Furthermore, in order to meet customer expectations in product demands and services, manufacturing firms must implement an integrated digital supply chain process. Because integrated supply chain firms provide consumers with digital enablers such as smartphones, computers, tablets, and virtually "unrestricted" access to the internet from the comfort of their homes, at work, 
in stores, or on the go, they now have a competitive advantage over the supply chain layer, allowing them to access products anywhere, at any time, and through any sales and marketing channel. Since the cloud, computing has emerged as one of the foremost enablers of the manufacturing industry's performance and efficiency [13]. Effective and efficient supply chain integration achieves the well-defined flows of products and services, information, money, and decisions, to supply maximum value to the customer at low cost and high speed [4]. Also, technological innovations, platforms, and applications present tremendous potential in terms of access to previously untapped sources of data [24]. This can enhance the performance and competitive advantage of the firms. However, to boost the interaction and collaboration among manufacturing supply chain stakeholders on the various phases of the firm, including planning, design, manufacturing, logistics, and performance measurement, a system is crucial. While currently the firm applies digital technologies, thus digital technologies have become inevitable across all business functions, providing opportunities in marketing processes, business structures, systems, processes, and, especially, human capabilities, all must evolve to reflect and exploit this opportunity [22]. Besides, the shortage of integration and poor collaboration are the foremost defects within manufacturing firms [2]. Furthermore, technological inefficiency impacts the final performance and competitiveness of supply chain firms [3]. During the evolution and revolution of the digital age, digitalization and technology advancements have had great impacts on the manufacturing industries through supply chain systems. The challenge in these business environments is, namely, not just to want supply chain integration enablers but to implement them successfully. Thus, adoption and implementation of cloud, computing systems on firm performance are crucial. Furthermore, cloud manufacturing continues to be in its infancy and a variety of other companies are already developing platforms for commercial purposes [13]. Supply chain integration with cloud computing is at its most effective, but still emergent in terms of both theory and practice.

Globally, cloud computing strategies have been used in the supply chain integration process, which provides a link between customers, retailers, manufacturers, and suppliers who, using management techniques, work together to optimize their collective performance within the creation, distribution, and support of an outcome (Lassar, Haar, Montalvo, \& Hulser, 2009), (Fabbe-Costes \& Jahre, 2007). But in Ethiopia, there's a weak traditional, fragmented, non-integrated, weak, and underdeveloped supply chain process [9, 4, 39]. This results in poor performance and competitiveness in manufacturing industries, while the ultimate goal of technology and digitalization is to satisfy consumer demand and enhance the competitiveness of organizations at various levels. Furthermore, the digital revolution, which includes cloud computing, internet technology, 3D printing, and big data analysis, helps manufacturing industries make better use of resources such as labor, inventory, quality, storage, process, technology, stock, and distribution capacity. Even if, within the present business environment due to the nuclear plate form, thanks to the protection of cloud technology, information visibility firms may possibly be scarified in various extents. Although normal relational databases are designed in an extremely different hardware and software era, they face challenges in meeting the performance and scale requirements of massive data [17, 40]. Similarly, thanks to the massive amount and style of knowledge existing in business environments, it's difficult to manage, realize the domain and even tougher to decide on an appropriate solution for a selected task. On the other hand, despite the importance of the essential metal industry sector to the Ethiopian economy, there's weak performance and global competitiveness in quality, flexibility, customer response, finance, innovation, technological capability [9, 4]. This will be due to poor, in-collaborative, technological in-efficiency, and non-integrated supply chain integration and business processes [1]. The primary challenges and constraints of regional basic metal industries are unbalanced demand and supply of the staple, poor product quality, insufficient technological capability, rock bottom level of business transformation, poor production capacity, weak manufacturing systems, and limited technological innovation $[38,10]$. Also, adoption, implementation, and managing big data processes within the business environments have been the key problems influencing the promotion of cloud computing applications within the provision chain process. Thus, investigating the big data management systems strategies within the cloud environments for supply chain integrations cannot only help users to elucidate their data more accurately and conveniently, but also helps them to control and optimize these data searching strategies to comprehend more accurate data information so as to provide more reliable higher cognitive operation support. Nevertheless, there's still space for research on real industrial applications where Ethiopian firms strive for cloud-based integration and implement new models and integration strategies practices in their supply chains. Furthermore, there is a niche in our sympathy for empirical evidence on the degree of supply chain integration, and limited research empirical evidence on the impacts of cloud-based supply chain enablers on performance to realize comparative advantage and global competitiveness of firms. In particular, up to now, there have not been any efforts to check from a search perspective the impacts of cloud-based supply chain integration on Ethiopian basic metal industries. The main objective of this study is to research the impacts of cloud computing technology on the availability chain integration process in order to boost the performance and comparative advantage of producing industries at national, regional, and global levels.

\section{Literature Review and Hypotheses Development}

\subsection{Supply Chain Integrations Through Cloud Computing}

In the digital connectivity and the new manufacturing 
process the three "Big" technology enablers includes the internet, the internet of things and cloud computing have great impact on the overall manufacturing systems performance and competitiveness [19]. Particularly the cloud computing technology transforms the way in which current enterprises IT infrastructure is constituted and managed through consumable services such as infrastructure, platform, and applications [30, 16].

\subsection{The Evolution of the Digitalization}

In the history of the availability chain the method, firms use various supply chains strategies in several ways at the various time. The transformation this strategy varies with time to time. The progress and advancements of supply chain strategies also considered as time dependents. Those supply chain development and revolution have traced and passed the subsequent phases, the revolution of logistical military operational solutions, transportation management systems, the logistics, and physical distribution, fragmental logistics process from 1940s-1960s were worked and used. during this stage, better focus was also placed on warehousing and handling process by the organizations. While within the early 1980s, (1970s-1980) ineffective supply chain decisions were taken from principally functional perspective. This era are considered as a change process and planning and operation process wiped out an isolated manner. This can be the tradition systems of supply chain and logistics. Next the transformation and provide chain incremental phase (1980s-1990s) were the advantages of aligning organizations, together with the associated business objectives [21, 3]. This stage is that the transition period for contemporary supply chain system and also the negative effects of individual business underlined by corporate leaders. Additionally, for executives and underlying business processes performance incentives, cost reduction through the technological application and also the importance of IT base planning were developed [3, 29]. This era is additionally, the age of specialization, companies improve their overall competence within the same way that outsourcing manufacturing and distribution has done and focused on their core competencies and assemble networks on best class domains specific partners to contribute the value chain and improve the performances of the systems. Generally, the advancement, evolution and revolution of supply chain systems during a business process are explore within the figure 1 below. in line with this figure supply chains are advanced in both systems and technological wise at higher extents. These evolution and revolution of supply chain system and provide chain process result to impact the performance and competiveness of producing industries at higher extent.

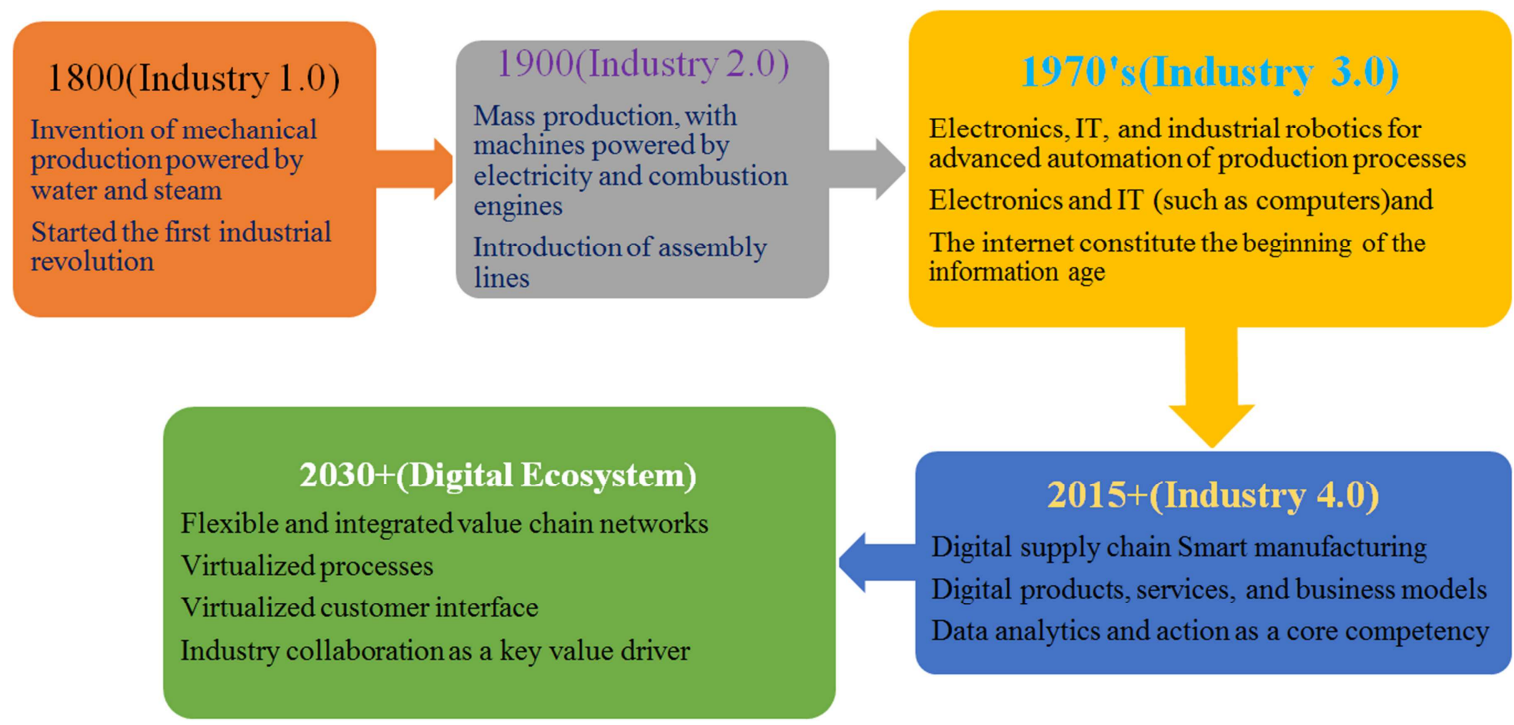

Figure 1. Digital evolution and revolution process on supply chain integrations, (The Author adopted from [31].

\subsection{The Enablers of Digitalization and Digital Revolutions}

The social media, big data, the internet of things, mobile computing and cloud computing are technological trends that influence on production processes, products, services and business strategies significantly [34, 35]. Particularly in the digital connectivity and the new manufacturing process enablers have great impact on the overall performance of manufacturing systems and productivity of the firms [23, 29]. Literally, digitalization is a tool for renewal, simplification and improvement that must be incorporated into our approach to principle, strategies and development policy. Therefor the adaptation and implementation of digital technologies including internet of things (IoT), cloud computing, big data analytics (BDA), Automation and Robotics are the main technologies and solutions which have accelerated digital transformation in a business environments [23].

\subsubsection{The Internets}

The internet enables global movement of data and information almost everywhere as the programmer ordered. In a supply chain systems the internet have the greatest potentials and provides to speeding up communication between customers and their 
suppliers, improving service levels, reducing logistics costs, contributes to enhancing firm performances. However firms greatly increase the size of the accessible market through the Internet goods and services can sell world-wide. Currently, in supply chain process the internet has revolutionized supply chain with inventory management, purchasing, transportation, order processing, vendor relationships and customer service process $[15,19]$. Thus the application of interne technology has enabled companies to be more responsive to their customers and enhance business - to - business supply chain integration [26].

\subsubsection{The Internet of Things (IoT)}

The internet of things (i.e., devices and sensors connected to the internet) enables to data capture from and provides information to various entities of supply chains systems. The internet of things is revolutionize decision making process that connecting the previously unconnected, systems to create incredible potential for businesses to improve the speed and accuracy of decision making through the analysis and application of digital information [15]. This enables dramatically faster cycle times, highly dynamic processes, adaptive customer experiences and, through the ecosystem of people and technology, the potential for breakthrough performance gains. Though, IoT is provides to interconnected network of smart objects using the Internet, sensors, and RFID is able to transfer data without human interaction over the network [31]. While, the IoT provides to needs enhanced processing power device with large storage capacity having always-on connectivity, so as to transfer data to the exacted segments.

\subsubsection{The Cloud Computing}

Cloud computing is a web based computing which has powerful computational architecture and it offers universal services to the shoppers and it's several benefits over grid and other computing [27]. Cloud computing technology provides to as a possible tool to support the performance of varied sector in a very supply chain management [20]. As well, a cloud computing emerges as a meaningful technology that would contribute to optimization the price and operational efficiency of the availability chain systems by providing infrastructure platform and software solutions for the full supply chain network through internet [14]. [27] shows that the cloud computing are often considered a brand new computing paradigm that permits users to temporary utilize computing infrastructure over the network, supplied as a service by the cloud-provider at possibly one or more levels of abstraction.

Cloud computing isn't a brand-new technology, but today it's one in every of the foremost emerging technology thanks to its powerful and important force of change the way data and services are managed [36]. Within the meantime in today business systems cloud computing providing to attenuate the value and maximize the efficiency each systems of the firm. This provides the cloud computing is handle multiple process and improve the performance of procurement, manufacturing, and distribution systems. Also, the effective and efficient adoption of cloud computing can improve the organizational performance in terms of cost, quality, speed, and adaptability of supply chain firms [5]. Furthermore the cloud computing used as an optimizing technology that contributes to optimize by providing infrastructure, platform and software solutions for the full supply chain systems. In additionally, the cloud computing launch flexibility within the way a corporation conducts its business, to realize their competitiveness and performance improvements. This provides that the cloud computing systems are a strong to boost flexibility, agility, quality, visibility and performance on the assembly of the firm. As a results of the effectiveness of the systems any organizations, individuals should adopt this cloud computing systems in their business process. Moreover, study [27, 33] shows that, the cloud computing can provide on-demand computing services with high reliability, scalability and availability during a distributed environment.

Besides the study [7] investigate the effect that cloud computing technology has on collaborative advantage and relational outcomes in small and enormous organizations. During this context cloud computing used as integration and collaborative tool, so on improve the performance of firm. Thus organizations implement cloud computing systems to boost collaboration, coordination and cooperation between the cloud partners on each segment.

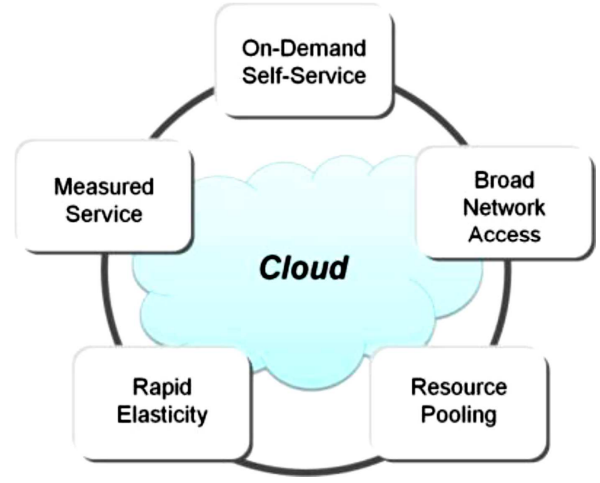

Figure 2. Cloud Computing characteristics, Source. (Distefano, 2015).

The figure above shows the peculiar characteristics the cloud computing paradigms. Besides the management of the cloud computing (CC) system services is an inherent vulnerability in a CC environment, not only because of the virtualization and accompanying vulnerabilities, but also because of certain other reasons [12]. Since the cloud computing management's system services management lies in the enormous increase of digital information in the world, and an ever-more difficult and more complex management of the so-called digital universe and big data.

Nevertheless cloud computing offers many benefits to organizations, but these benefits are likely to be undermined by the failure to ensure appropriate information security and privacy protection when using cloud services, resulting in reputational harm, higher costs and potential loss of business. Furthermore the adoption, implementation and the importance of cloud computing systems are varies from one sector to another. As a result of this it needs critical selection and implementation of the cloud computing systems on manufacturing firm. Thus to enhance efficient business 
process and apply right infrastructure in the company's entire systems via the internet, appropriate cloud computing systems are adopted [5, 41]. In place of a result effective data management systems through cloud computing technologies are essential to resource utilization, operational efficiency, customer centricity, compliance, agile distribution systems, and, the overall success and competitiveness of firm.

\subsection{The Importance and Values of Cloud Computing to Manufacturing Industries}

In the cloud computing system the technology use various futures including standardization technology, virtualization technology, data management technology, platform management technology in data flow and information collaboration of firm [8]. Contrariwise, the cloud data management systems provides to two or more manufacturing firms linked together by the provision of cloud services, related information and funds, so as to enhance mutual benefits.

For Business process the cloud computing provides to have different function and benefiters including monitoring measuring, planning, controlling, learning, optimizing, automating on supply chain firm.

\subsubsection{Monitoring and Controlling Process}

In business process, the cloud computing systems enables both consuming and providing organizations to clearly determine their position within such a data management systems. Since using cloud computing systems the shipments, assets, employees, requirements, risks condition of organizations are monitored. Also the cloud computing can be used to mitigate the risks associated with the implementation and deployment of RFID based on system in supply chain management [29]. Since, cloud computing provides to monitoring and product control from manufacture to retail sail including its distribution.

\subsubsection{Measuring}

The cloud commuting systems are provides to use measurements automatically optimize resource use storage, processing and test the whole performance of the stems [6].

\subsubsection{Planning}

In the current manufacturing firms, the cloud-based tools are used to provide capturing itemized spend data, performing basic analytics, planning manufacturing runs and executing statistical demand forecasts. Although, the cloud systems are applicable in planning and resource allocation, assortment and space, pricing and promotion, product sourcing \& procurement, forecasting and replenishment process have critical impacts on the big data management systems. As well in planning process the cloud computing are helps to organizations in how manufacturing enterprises operate, how they integrate into their systems, or how products are designed, fabricated, and used by customers, done so as to enhance manufacturers innovate, reduce costs, and increase their competitiveness [34]. Though, the cloud computing through, information technology provides to transforming the global manufacturing economy by digitizing virtually every facet of modern manufacturing processes. Even though, the spread and technology of cloud computing in big data management systems are still in their early stages, the technology itself is largely proven. Thus, organizations should implement this cloud computing systems so as to improve their performance and competitiveness through big data management systems.

\subsubsection{Automating}

The cloud computing systems are essential for automated processes, control transactions, assist regulatory compliance, and assist in delegating changes in hardware and software resources in a big data management process. In addition the automated data management systems used to identity management capabilities, to ensure a proactive response capability of the entire business process and system [6, 35]. As well the use of cloud computing systems, in big data management systems companies are developing new and better ways to quickly information shearing, efficiently deliver of product and services, developed improved systems on the firm business process. As well cloud computing provides to enhance the scalability ensures that computing services available to the users at any point in time.

\subsubsection{Optimizing}

Due to extremely high volume of data generated in warehouse systems, the process needs for automation and optimization process. However, using cloud computing and information technology infrastructure the warehouse inventory status files, associated inventory location and integration of specific customer order status tables including order payment, and order fulfilment status is integrated using cloud computing systems [33]. However this large amount of data and information in warehouse systems are handled by the cloud computing and information technology infrastructure. This handling and systems are provide to improve the efficiency, visibility, fast response and utilization of resources in the systems. Since cloud based big data management and information technology systems are essential to businesses process to optimize operations and retail, manufacturing and other industries.

\subsection{Role and Impacts of Cloud Computing Technology on Supply Chains Revolutions}

A number of technologies from sensors to cloud services big processing enable to drive digital trends. Within the current digital revolution, digital supply chains have the aptitude for extensive information availability and superior collaboration that end in improved reliability, agility and effectiveness of the firms [18]. Currently digitization brings down those walls, and also the chain becomes a totally integrated ecosystem that's fully transparent to all or any the players involved from the suppliers of raw materials, components, and parts, to the transporters of these supplies and finished goods, and at last to the purchasers demanding fulfillment [21, 25]. Additionally, digital supply is access to customer demand has to be shared effectively, and products and repair deliveries must be tracked to supply visibility within the supply chain $[16,32]$. An additionally digital system provides to support data acquisition, 
communication, and every one decision-making activity [39]. Since, digital supply chain gives to reinforce efficient and effective design and operation process of a producing system. It also provides to effective business activities, prompt and effective decisions making process in supply chain firms.

\subsubsection{Firm Flexibility}

Flexibility provides to administer the organization more room and talent to retort quickly to unpredicted changes [3]. Digital supply chain provides to carte flexible environment through, greater freedom to settle on the acceptable degree of centralization needed to support specialization or minimize process costs given different local labor costs and productivity levels across locations.

As well, digital supply chain became more global, enabling collaboration between different players became even more essential. Additionally, digital supply chain used as a key enabling tool to the choice making in business process.

\subsubsection{Enhance Agility and Scalability}

Currently the capabilities for digital transformation are embedded within the enterprise and tightly linked to an agile management vision. Since, because the pace of change accelerated in markets, government regulations, customer needs and industry disruptions, the size of supply chain needed to adapt quickly to fulfill these shifts. Agility became essential to produce chain operation process. Thus agility is enhanced with well-organized digital supply chain systems. As well, in digital supply chain company management could achieve significant profit increases by reducing overhead expenses related to existing systems.

\subsubsection{Improve Productivity}

After exhausting productivity gains from traditional methods such LEAN, Six Sigma and other efficiency initiatives, Cisco wanted to seek out new ways to interrupt faraway from these nominal gains.

\subsubsection{Meet Changing Customer Expectations}

Cisco customers moved from viewing us as a supplier of hardware to a partner who provides solutions. to stay pace with these changing expectations, Cisco needed to redouble its concentrate on delivering the best customer satisfaction.

\subsubsection{Enhancing and Support New Innovation}

Continuous improvement could be a core business management philosophy for optimizing the systems. Though digital ecosystem awareness and feedback may be a constant input to business innovation. Since, Cisco had to strategize to support new innovation across a large range of latest technologies. Though, for the advancement of technology and digital systems innovation is that the specific tool of entrepreneurs, with the event of technical design, manufacturing, management and commercial activities involved within the marketing of a replacement (or improved) product or first commercial use of a brand new (or improved) process or equipment $[3,21]$. Optimized digital systems aggressively disruptive for the enterprise and impact markets of the business process [34, 37].

\subsubsection{Universal Order Visibility}

Digitization provides to cut back unnecessary time spent trying to spot issue holding up an order. Meanwhile, universal order visibility tracks orders in real time and creates near real-time order visibility dashboard views across supply chain for faster root cause analysis and improve systems. This provides to provide one source of knowledge, information and truth for all users by getting all the information together in one place with enabling devices (like computer and mobile). Thus, digitization are importance on supply chain systems to reduced manually scheduled, reduce and improved order schedule and helps to scale back backlog. While, within the current globalized economy manufacturing firms should adopt the worldwide outsourcing strategy and digitized systems to attain competitive advantage. Since, the sustainable competitive advantage of firms over its competitors is rely on success and effectiveness of companies. While supported the literature information the research hypothesis are developed for the empirical investigations.

\subsection{Hypotheses Are Formulated}

Extra ordinary supply chain integrations have been improved trough integrated and well-organized cloud computing and related digitalized technologies. Those technologies provide to improve speed, flexibility, performance, innovation, collaboration and cooperation's of firms in a supply chain process.

Therefore, we propose the following set of hypotheses:

H1: There is a positive relationship between adoption of cloud computing technology on supply chain integrations for firm performance and firm flexibility.

$H 2$ : The adoption of cloud computing have positive impact on SCI to Enhance Agility and Scalability in the firm.

H3: There is a positive relationship between clouds computing technology implementation on the supply chain integration for universal order visibility.

H4: There is a positive relationship between clouds computing technology implementation on the supply chain integration to Improve Collaboration and Cooperation's.

H5: There is a positive relationship between clouds computing technology implementation on the supply chain integration to implement new business models and innovation.

H6: There is a positive relationship between clouds computing technology implementation on the supply chain integration to Improve Supply Chain Security.

H7: There is a positive relationship between adoption of cloud computing technology in SCI for improve quality and productivity.

\section{Research Methodology}

\subsection{Research Design and Methods}

This study have been adopted a mixed research design approach involving both quantitative and qualitative research designs. The field observation and literature review on research articles, manuals, company report, and electronic-sources were employed in this study. 


\subsection{Sample size and Sampling Procedures}

The primary data have been collected from 86 Ethiopian metal and engineering industries (Automotive, machine tool, and basic metal industries) firms' tired using purposive sampling procedure. Mainly from medium to large industries, were considered to the study.

\subsection{Data Analysis and Interpretations}

Mainly the study mainly employed both qualitatively through descriptive analyses, and quantitatively the data were analyse and investigated using SPSS correlation and regression analysis methods and tools.

\subsection{The Reliability Test}

The psychometric constructs in this study were tested for internal consistency. Mainly the reliability analysis has been carried-out using Cronbach's alpha.

\section{Result and Discussions}

Due to changes in technology and customer expectations, companies which want to stay competitive increasingly need to digitize their production systems and services. However, digital supply chain provides to develop a digital strategy that embeds the right technologies for your business, understand and manage global supply-chain complexity and risks, optimize your global material, information and financial flows and lead organizational change and SC transformation [30, 11]. Typically the digital transformations have great impact to the firm in the supply chain process to integrate their business process to global markets. As a result nations, organizations, firms and individuals try to access and connect their systems to the globs.

Table 1. The impacts of digitalization on supply chain performances.

\begin{tabular}{|c|c|c|c|c|c|c|c|}
\hline \multirow[b]{2}{*}{ Technological Revolutions } & \multicolumn{7}{|c|}{ Performance indicator } \\
\hline & $\begin{array}{l}\text { Enhance Speed } \\
\text { and Flexibility }\end{array}$ & $\begin{array}{l}\text { Enhance } \\
\text { Agility and } \\
\text { Scalability }\end{array}$ & $\begin{array}{l}\text { Improve } \\
\text { quality and } \\
\text { Productivity }\end{array}$ & $\begin{array}{l}\text { Universal } \\
\text { Order } \\
\text { Visibility } \\
\end{array}$ & $\begin{array}{l}\text { New business } \\
\text { models and } \\
\text { innovation }\end{array}$ & $\begin{array}{l}\text { Improve } \\
\text { Collaboration and } \\
\text { Cooperation's }\end{array}$ & $\begin{array}{l}\text { Improve } \\
\text { Supply Chain } \\
\text { Security }\end{array}$ \\
\hline Internet (IE) & 0.03 & 0.03 & 0.02 & 0.02 & 0.03 & 0.03 & 0.01 \\
\hline Internet of things (IOT) & 0.045 & 0.05 & 0.04 & 0.05 & 0.05 & 0.05 & -0.02 \\
\hline Cloud Computing (CC) & 0.035 & 0.05 & 0.035 & 0.04 & 0.04 & 0.04 & -0.03 \\
\hline Big Data Analytics (BDA) & 0.03 & 0.04 & 0.03 & 0.03 & 0.03 & 0.04 & 0.03 \\
\hline
\end{tabular}

This empirical analysis has investigated the impacts of digitalization and digital technology to supply chain integration performance for the manufacturing. Generally the application and implementation of digital technologies have great impact on the performance and competitiveness of manufacturing industries [39, 24, 2]. Particularly the cloud computing, internet technology, big data analysis, and the internet of things (IoT) have a great positive impact in the supply chain performances to regional integrations interims of speed and flexibility, enhancing firm agility, new business models and innovation, universal order visibility, improve collaboration and cooperation's process. Nevertheless, impacting the levels to supply chain performances are different from scenario to scenarios. For instance, in the table above shows that digital technology has highest positive impact on to enhance supply chain agility, lowest positive impacts on improve quality and productivity to manufacturing industries. While, technological revolutions for enhancing agility, improve collaboration and cooperation's, new business models and innovation, universal order visibility, speed and flexibility, quality and productivity have positive impact on supply chain integrations of manufacturing industries from the highest to the lowest respectively, supporting $\mathrm{H} 1, \mathrm{H} 2$, and $\mathrm{H} 3$. Therefore, promoting the adoption and implementation of digital technology including cloud computing, internet of things, internet technology, and big data analysis have highest and positive impact on the overall performance of supply chain integrations to the regional industries shown in the figure below.

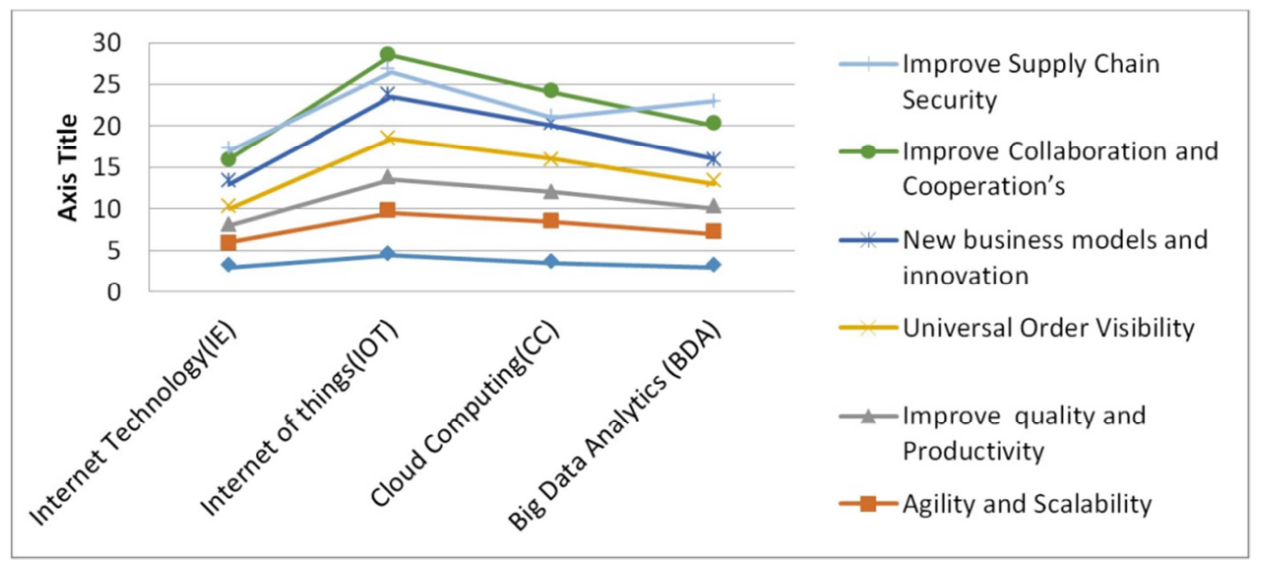

Figure 3. The impacts of digitalization to supply chain performances. 
These in the empirical result supports in a such a way that digitalization have provides to superior collaboration and communication across digital platforms resulting in improved reliability, agility and effectiveness to manufacturing industries [18]. Particular digitalization provides to make companies to turn their supply chain process from into to end-to-end business operating strategies [30]. These results to enhance the performance and the overall comparative advantage of manufacturing industries. Besides, in table 2 empirical result shows that cloud computing technology has a negative impact on supply chain performances interims of supply chain security and privacy policy. Because digitalization and cloud based technology are highly increase the visibility, information shearing and accessibility of the data and information's in the cloud environments. Every data should be scurried, and granted otherwise it is highly hacked by various data and information hackers. The is occurred because of lack of knowledge, lacking sense of urgency, excessive complexity, and increased security risk in the cloud computing and digital technology implementation and application process.

Table 2. Cloud Computing Based supply chain roles on performances.

\begin{tabular}{|c|c|c|}
\hline Cloud Computing Role Performance Indicators & Correlation Results & Remark \\
\hline $\begin{array}{l}\text { Positive relationship between adoption of cloud computing technology on supply chain integrations for firm } \\
\text { performance and firm flexibility (H1) }\end{array}$ & 0.035 & Supported \\
\hline Adoption of cloud computing have positive impact on SCI to Enhance Agility and Scalability in the firm (H2) & 0.05 & Supported \\
\hline $\begin{array}{l}\text { positive relationship between clouds computing technology implementation on the supply chain integration for } \\
\text { universal order visibility (H3) }\end{array}$ & 0.04 & Supported \\
\hline $\begin{array}{l}\text { positive relationship between clouds computing technology implementation on the supply chain integration to } \\
\text { Improve Collaboration and Cooperation's (H4) }\end{array}$ & 0.04 & Supported \\
\hline $\begin{array}{l}\text { There is a positive relationship between clouds computing technology implementation on the supply chain } \\
\text { integration to implement new business models and innovation (H5) }\end{array}$ & 0.04 & Supported \\
\hline $\begin{array}{l}\text { positive relationship between clouds computing technology implementation on the supply chain integration to } \\
\text { improve supply chain Security (H6) }\end{array}$ & -0.03 & $\begin{array}{l}\text { Not } \\
\text { Supported }\end{array}$ \\
\hline $\begin{array}{l}\text { There is a positive relationship between adoption of cloud computing technology in SCI for firm competitiveness } \\
\text { and Comparative advantages (H7) }\end{array}$ & 0.035 & Supported \\
\hline
\end{tabular}

Furthermore the potentials of cloud computing base supply chain integrations provides to enhance firm performance, the cloud computing security, visibility and cloud architecture are still questionable which impacts the cloud model adoption and implementation in manicuring industries. Likewise due to model architecture, multi-tenancy, elasticity, elements of application, network, data, and layers dependency stack, the cloud computing security problem becomes more complicated under the cloud model as new dimensions [14]. In this scenario cloud computing and related digitalized technologies adoption and implementation in supply chain process have a negative impact on the risk and security issue of firms within supply chain segments. The investigations also perceive that some of the security issues are inborn from the used technologies or poor clod systems and improper adoption and implementation of the cloud computing platform. While in case of information technology and cloud base systems risks are part of normal business process in a firm. Nevertheless it is unrealistic and it is extremely expensive to eliminate all risks in IT cloud base service rather reducing it.

Lack of knowledge, lacking sense of urgency, excessive complexity, and increased security risk during digitalized supply chain systems. As more information is shared online, there is more incentive for hackers to find ways to get through your security are the main most critical challenges for digital transformation on business process. Therefore the type and level of cloud computing digitalized technologies have not a positive impact on the performance of supply chain integrations in line to security and privacy policy issue, H6 not supported.

\section{Conclusion, Implication and Recommendation}

\subsection{Conclusions}

In this study, we have to discuss the impacts, trends, roles, characteristics, and strategies of digitalization and cloud computing technology on business performance. Moreover, the study shows the impact and roles of cloud-based supply chain integration on manufacturing industry performance and competitiveness have been studied and investigated. The paper also shows the role of digital technology in the current globalized world. The advancement of technology and digital schemes are doing for mental power. Mostly, digitalization provides us with the ability to use our brains to understand and shape our environments, much like what the steam engine and its descendants did for muscle power. The study shows, using primary and secondary data, that digitalization in the form of cloud computing, internet technology, big data analysis, and internet of things technology has had a significant impact on the performance and competitiveness of the manufacturing and services industries. But the roles and the impact of those technologies on the supply chain integration process are different from scenario to scenario. The advancement of digital technology, particularly cloud computing technology, has the greatest impacts on people and business environments as supply chain enablers. Thus, to any extent, level, and organizational scenario, the cloud-based supply chain integration process has greater positive impacts on the 
performance and competitiveness of a firm. Therefore, the adoption and implementation of cloud-based supply chain integration within companies needs to be validated based on their own server infrastructure, whether they are based on their own server infrastructure, on or off premise cloud platform, or otherwise outsourced. Thus, according to this study, digitalization and digital technology are considered very promising technologies that allow organizations to effectively manage their resource limitations with the slightest amount of capital investment and meet dynamic demands efficiently. But the nations' contributions are limited and at infant stages. In the developed economy, the contributions are in lower ranges, usually below $20 \%$. Furthermore, the cloud computing and digital technology implementation, as well as the cloud-based supply chain application process, have a negative impact on performance due to a lack of knowledge, a lack of urgency, excessive complexity, and increased security risk. Because digital technologies have a higher level of visibility, and flexibility in terms of resources, security in supply chain integrations. Thus, security and sustainability issues are the main constraints of digital technology and cloud computing technology implementations, and to these extents, technologies have a negative impact on supply chain performance. Thus, during the adoption and implementation of cloud based supply chain systems in manufacturing industries, any business process should be highly considered for security and visibility issues.

\subsection{Management Implications and Suggestions}

This study presents important findings on cloud-based supply chain integration and digital technology roles in relation to firm performance and competitiveness. Established in cloud-based supply chain integration, including internal integration, process and production integration, logistics processes have a higher positive impact on cost optimization, product sourcing, and procurement strategy, strong customer fulfillment, flexibility, speed, and productivity of manufacturing and services industries. But adoption and implementation of cloud-based supply chain integrations are scenario and contextual-based. Based on firm context, the proper adoption and implementation of cloud-based supply chain integrations has a higher positive impact on firm performance and competitiveness. Thus, our managerial implications suggest that managers should analyze and consider their business processes and systems, as well as manufacturing practices. Based on their manufacturing practices, they have to adopt and implement innovative and cloud-based supply chain strategies. The resulting insights can be used to decide on effective encouragement focus. Next, we propose a managerial tool that companies may use to automate the cloud-based supply chain integration process. By setting available strategies in parallel, they should be able to handle the impacts and influence of security and supply chain risks.

Since digital and cloud based supply chain integration have a great positive impact on the supply chain's performance, regional integration interims of speed and flexibility, enhancing firm agility, new business models and innovation, universal order visibility, and improving collaboration and cooperation processes. But cloud computing and related digitalized technologies' adoption and implementation in supply chain processes have a negative impact on the risk and security issues of firms within supply chain segments. More research is needed to overcome security and risk challenges in digitalized and cloud-based supply chain integration.

\section{References}

[1] Agorasti Toka, E. A.-D. (2013). Cloud Computing in Supply Chain Management: An Overview. Aristotle University of Thessaloniki, Greece: IGI Global.

[2] Alie Wube Dametew, B. B. (2016). Study Supply Chain Integration to basic Metal Industry. Industrial Engineering, 16 (2).

[3] Alie Wube, D., \& Frank, E. (2017). Technological Innovations as a Potential Vehicle for Supply Chain Integration on Basic Metal Industries. International Journal of Swarm Intelligence and EvolutionaryComputation, 6 (2).

[4] Alie Wube, D., Frank, E., \& Birhanu Beshah, A. (2016). Supply Chain Integration for Improving Performance on Manufacturing Industries. Journal of General Engineering, 16 (4).

[5] Al-jawazneh, B. E. (2016). The Prospects of Cloud Computing in Supply Chain Management (A Theoretical Perspective). Journal of Management Research, 8 (4).

[6] Attaran, M. (2017). Cloud Computing Technology: Leveraging the Power of the Internet to Improve Business Performance, Journal of International Technology and Information Management, 26 (1).

[7] Aviles, M. E. (2015). The Impact of Cloud Computing in Supply Chain Collaborative Relationships, Collaborative Advantage and Relational Outcomes. Electronic Theses \& Dissertations. 1244. Georgia Southern University.

[8] Berkha jain, R. D. (2015). Implementation of Cloud Computing In Supply Chain Management. International Journal for Research in Applied Science \& Engineering Technology (IJRASET), 3 (7).

[9] Bete Georgise, F., Klaus-Dieter, T., \& Marcus. (2014). Identifying the Characteristics of the Supply Chain Processes in Developing Country: A Manufacturing Industry Perspective. WSEAS TRANSACTIONS on BUSINESS and ECONOMICS, 11.

[10] Dagne Birhanu, D.-I. D. (2009). Small Scale Metalworking Industries Cluster (Case Study on Towns of Oromia Special Zone). Addis Ababa: Un-published work.

[11] Distefano, M. (2015). Cloud Computing and the Internet of Things: Service Architectures for Data Analysis and Management. University Of Pisa Department Of Computer Science (Ph.D. Thesis Proposal).

[12] Grubor, G. (2015). Introducing the Information Security Management System in Cloud Computing Environment. Introducing the Information Security Managment System in Cloud Computing Environment.

[13] Han, Z. (2015). Cloud computing contribution to manufacturing industry. UNIVERSITY OF TURKU, Department of Management and Entrepreneurship, Turku School of Economics. 
[14] Huotari, J. T. (2013). ADOPTING CLOUD COMPUTING AND HOSTED SERVICES IN PHARMACEUTICAL INDUSTRY. Degree Programme in Information Technology Technology and transportation.

[15] James Macaulay, L. B. (2015). INTERNET OF THINGS IN LOGISTICS. 53844 Troisdorf, Germany: DHL Customer Solutions \& Innovation.

[16] Kari Korpela, J. H. (2017). Digital Supply Chain Transformation toward Blockchain Integration. Proceedings of the 50th Hawaii International Conference on System Sciences.

[17] Katarina Grolinger, W. A. (2013). Data management in cloud environments: NoSQL and NewSQL data stores. Grolinger et al. Journal of Cloud Computing: Advances, Systems and Applications, 2 (22).

[18] Martin Raa, B. G.-C. (2011). Digital Transformation of Supply Chains; Creating Value - When Digital Meets Physical. Capgemini.

[19] Miller, D. (2016). The Role of the Internet in Supply Chain Management Management. Online Business Articles.

[20] Muhammad Abedi, M. S. (2013). The Impact of Cloud Computing Technology to Precast Supply Chain Management. International Journal of Construction Engineering and Management, 13-16.

[21] NilsUrbach, P. D., \& Jeanne, R. (2017). Digital Business Transformation and the Changing Role of the IT Function. MIS Quarterly Executive, 6.

[22] O'Hea, K. (2011). Digital Capability How to Understand, Measure, Improve and Get Value from it. IVI Inovative value institute.

[23] Pieriegud, J. (2018). DIGITAL TRANSFORMATION OF RAILWAYS. Siemens Sp. z o. o., Poland: Department of Transport SGH Warsaw School of Economics, ProKolej Foundation.

[24] Prepletaný, D. (2013). The Impact of Digital Technologies on Innovations in Retail Business Models. AALBORG UNIVERSITY, International Marketing.

[25] R. Arokia Paul Rajan, S. S. (2012). Evolution of Cloud Storage as Cloud Computing Infrastructure Service. IOSR Journal of Computer Engineering (IOSRJCE), 38-45.

[26] Rahman, Z. (2004). Use of Internet in supply chain management: a study of Indian companies. Industrial Management \& Data Systems, 104 (1), 31-41.

[27] Rajleen Kaur, A. K. (2014). A Review Paper on Evolution of Cloud Computing, its Approaches and Comparison with Grid
Computing. International Journal of Computer Science and Information Technologies, 6060-6063.

[28] Ratlif, D. D. (2016). Digital Connectivity and the Future of Supply Chains \& Logistics. Gorgiya Intitute of Technology the logistics research center.

[29] S. M. Khalid Jamal, A. O. (2013). Cloud Computing Solution and Services for RFID BasedSupply Chain Management. Advances in Internet of Things, 3, 79-85.

[30] Saideep Raj, A. S. (2014). Supply chain management in the cloud. Accenture.

[31] Sanket Thakare, A. P. (2016). The Internet of Things Emerging Technologies, Challenges and Applications. International Journal of Computer Applications, 149 (10).

[32] Schrauf, S. (2016). www.strategyand.pwc.com. Retrieved from www.strategyand.pwc.com.

[33] Shalini Gupta, E. C. (2014). Optimizing Supply Chain Distribution usingCloud based Autonomous Information. Int. $J$ Sup. Chain. Mgt, 3 (4), 79-90.

[34] Simon Ellis, K. K. (2017). Digital Transformation Drives Supply Chain Restructuring Imperative. Digital Transformation Drives Supply Chain Restructuring Imperative.

[35] Stephen Ezell, B. S. (2017). How Cloud Computing Enables Modern Manufacturing. ASI.

[36] Tinankoria Diaby, B. B. (2017). Cloud Computing: A review of the Concepts and Deployment Models Deployment Models. I. J. Information Technology and Computer Science, $6,50-58$.

[37] Truong, D. (2014). CLOUD-BASED SOLUTIONS FOR SUPPLY CHAIN MANAGEMENT: A POST-ADOPTION STUDY. ASBBS Annual Conference: Las Vegas, Volume 21 Number 1. Las Vegas.

[38] Yared Lemma, D. K. (2014). The Impact Of Foreign Direct Investment On Technology Transfer In The Ethiopian Metal And Engineering Industries. INTERNATIONAL JOURNAL OF SCIENTIFIC \& TECHNOLOGY RESEARCH, 3 (4).

[39] Zhuming Bi, L. D. (2014). Internet of Things for Enterprise Systems of Modern Manufacturing. IEEE TRANSACTIONS ON INDUSTRIAL INFORMATICS, 10 (2).

[40] Alie Wube Dametewa*, Birehanu Beshah b, Frank Ebingerc, The Challenges and Practice of Metal Industries into Global Supply Chain Integration: A Literature Review, Tailor and fancies, Cogent Engineering, journal of Production \& Manufacturing, Volume 7, Issue 01, 2020, https://doi.org/10.1080/23311916.2020.1762523 